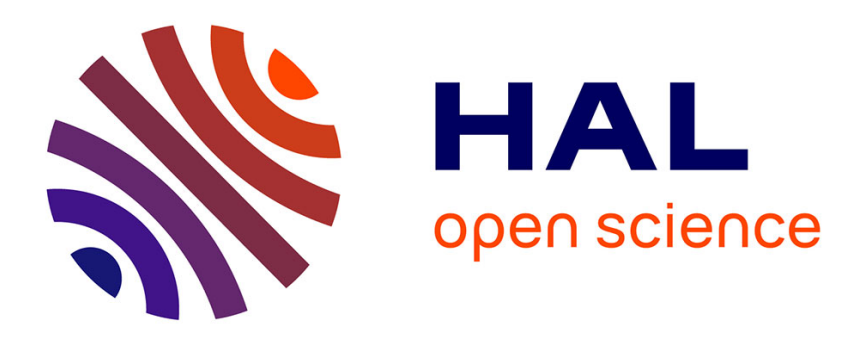

\title{
Freight Flows and Urban Hierarchy
}

David Guerrero, Laurent Proulhac

\section{To cite this version:}

David Guerrero, Laurent Proulhac. Freight Flows and Urban Hierarchy. Research in Transportation Business and Management, 2014, 17p. 10.1016/j.rtbm.2013.12.001 . hal-00954764

\section{HAL Id: hal-00954764 https://hal.science/hal-00954764}

Submitted on 3 Mar 2014

HAL is a multi-disciplinary open access archive for the deposit and dissemination of scientific research documents, whether they are published or not. The documents may come from teaching and research institutions in France or abroad, or from public or private research centers.
L'archive ouverte pluridisciplinaire HAL, est destinée au dépôt et à la diffusion de documents scientifiques de niveau recherche, publiés ou non, émanant des établissements d'enseignement et de recherche français ou étrangers, des laboratoires publics ou privés. 


\section{FREIGHT FLOWS AND URBAN HIERARCHY}

David GUERRERO ${ }^{1}$, University Paris EST, IFSTTAR, AME-SPLOTT² , david.guerrero@ifsttar.fr Laurent PROULHAC, University Paris EST, IFSTTAR, AME-LVMT, laurent.proulhac@enpc.fr

\section{ABSTRACT}

Varying hierarchy of freight flows between urban areas is the focus of this study. The results of a French survey that describes shipments sent by firms are used for understanding freight flows. The survey shows that the pattern of freight flows between urban areas in France is hierarchical, but varies depending upon whether the flows are generated by wholesale trade activities or by manufacturing. The differences are explained by the specific organizational characteristics of each of these two activities. Wholesale trade broadly reflects the traditional spatial organization of service activities, with interlocking areas of influence. The spatial organization of manufacturing flows is more complex, which can be attributed to the regional specialization of activities.

Keywords: freight transport, urban hierarchy, manufacturing, wholesale trade, France

\section{INTRODUCTION}

Urban centers are not isolated as they maintain intense relations with their immediate surroundings and with other urban centers. Scholars have long recognized that the classification of an urban center is linked to its position in the network of interurban exchanges. To describe the position of the urban center in the network, researchers often employ the notion of hierarchy, implying that relations between urban centers can be represented by a tree structure, characterized by a rank/size distribution. In some cases, the hierarchy is just a ranking of urban centers based on population distributions (Zipf, 1941) while in other cases the criterion is functional differentiation (Lyons and Salmon, 1995) or integration into global networks (Sassen, 1991). These studies usually rank the most visible and obviously dominant cities at the top: New York, London, and Tokyo in global hierarchies (Sassen, 1994), and London and Paris at the European level (Friedman, 1986, Hall, 1993). However, the criteria used to empirically situate urban centers within such hierarchies is limited to highly selective features, such as the presence of advanced service producers in

\footnotetext{
${ }^{1}$ Corresponding author

2 IFSTTAR, AME-SPLOTT, 14-20 Boulevard Newton, Cité Descartes, Champs sur Marne, F-77447 Marne la Vallée Cedex 2, Tel : +331816687 90. E-mail address: david.guerrero@ifsttar.fr
} 
those centers for example (Beaverstock, Taylor, and Smith, 1999), and often do not take into account the basis of urban hierarchies. Studies that integrate the top and bottom of urban hierarchies remain scarce (Rozemblat and Pumain, 1993), and such studies focus only on corporate links between companies.

Among the multiple features that are used to define interurban networks, perhaps the most attention has been devoted to transportation networks (Neal, 2011) and the focus is more specifically on passenger flows. Besides a few studies that looked at other means of transport (see for example Green, 1958, Godlund, 1956 on coach networks), most of these works are focused on air links. In this respect, the pioneering study by Taaffe (1962) on connections between urban areas in the United States demonstrated that air networks were strongly hierarchical at the beginning of commercial aviation (the major centers were New York, Chicago, Los Angeles, and San Francisco). Deregulation and a series of technical changes starting from 1978 radically modified market conditions in the United States (Goetz, 1992) and across the world (Goetz and Graham, 2004). Thus the evolution of aviation has led to significant changes in connectivity and flow patterns, notably through the emergence of hub-and-spokes networks (Ivy, 1990). While the major urban centers keep their dominant position in the air network (i.e., New York, London, Paris, Tokyo), the strategies of airlines dictate the roles and positions of other urban centers that keep shifting considerably (Shaw, 1993, Smith and Timberlake, 2001). It nonetheless remains true that the vast majority of medium-sized and small urban centers remain at the periphery of the air network despite the advent of low-cost carriers serving secondary airports (Dobruszkes, 2006). Insofar as these secondary urban centers are at the periphery of or absent from the air network, the aspect of their interurban relationships has been kept out of these studies.

The purpose of this paper is to help fill this void, by integrating higher and lower levels of urban hierarchy. In order to do this, freight flows are analyzed to understand what they highlight on the economic interactions between the urban centers. However, beyond simply deploying a new indicator to analyze interurban relationships, the article seeks to elucidate the roles of urban centers of different sizes in the transport system. The rest of the paper is structured as follows. The next section sets out our hypotheses and outlines the data and methods used. Section 3 analyzes the location of the manufacturing industry and wholesale activities. Section 4 describes the distribution of freight flows between urban centers as it relates to their size. It proposes a macroscopic approach to examine the spatial organization of productive systems. The final section offers some concluding remarks and identifies main research priorities.

\section{METHODOLOGY}

\section{Data}

The analyses are based on the 2004 French national shipper survey $\mathrm{ECHO}$, which threw light on transport practices and their logistical determinants (Guilbault, M., Gouvernal, E., 2010). Indeed, the survey becomes a useful tool for observing demand by shippers and by physical and organizational transport chains, from the shipper to the end consignee. The survey is mainly focused on business-to-business freight flows. The sample survey in the study consists of 2935 plants, 10,462 shipments, and 9742 complete transport chains. The 
scope of the survey covers all firms in mainland France, excluding Corsica, with 10 employees or more, operating in wholesale trade, manufacturing (excluding the extractive industries and construction), mail-order sales, agricultural cooperatives, warehousing services, and industrial waste processing centres. Overall, the survey covers approximately 70,000 plants and estimated after-adjustment transport volumes of 985 million metric tons and 738 million shipments (Guilbault, Soppé, 2009).

Moreover, the location of freight activities is identified using the SIRENE database for the year 2004. The survey also contains economic and spatial information on firms, in particular their plant (physical facilities operated by a firm or government department) and their jobs by business sector. Further, it identifies the location of economic activities within the national space and provides a detailed reading of the economic functioning of the flows generated by firms.

\section{The geographical area of observation of interurban flows}

This paper takes into account urban area (UA) to determine the organization of freight flows between the different levels of urban hierarchy. Then determining the urban unit of observation is important. The past decades were characterized by spatial deconcentration of activities, i.e., the tendency for jobs and logistics activities to move from urban to suburban areas (Dablanc, Ross, 2012). The urban sprawl results in an expansion of the urban perimeter in large areas. In this context, the scale of observation must include a wider definition of urban entities. We argue that the urban area is the most adapted scale to analyze interurban freight flows. We adopted the definition of the urban perimeter in this research from the French National Institute of Statistics and Economic Studies (INSEE) definition. The definition is that the urban area is a geographic unit that provides more than 10,000 jobs and includes a suburban unit in which at least $40 \%$ of the resident working population works within the central zone or within its catchment area.

\section{Methodological choices}

\section{Size classes of urban areas}

The shipper survey's fine stratification by firm activity and size means that its traffic data is statistically representative and it can be used for breaking down the activities economically into major production types. However, it should be kept in mind that the sampling plan does not include a regional breakdown or origin-destination analysis. This means that the shipper survey does not segment shipments by different levels of urban areas. In order to overcome this deficiency, the location (urban areas) of the firms' shipping and receiving freight flows were aggregated into several categories (appendix A). They were broken down into five levels by size of the urban area, ensuring that the total weight of each one was comparable in terms of population, jobs, and shipments (table I). The levels are as follows:

1. The Paris urban area

2. 18 large urban areas (with a population between 400,000 and 1.6 million), which include a dozen regional capitals "outside the Paris area" (i.e., Lyon, Marseille, Lille, Nice, Toulouse, Bordeaux, Strasbourg) 
3. 58 medium-sized urban areas (population between 100,000 and 399,000 )

4. 85 small urban areas (population between 40,000 and 99,000)

5. 189 very small urban areas (population less that 40,000 )

6. Rural areas.

Table I Background data on urban areas, aggregated by size category

\begin{tabular}{|c|c|c|c|c|c|c|c|}
\hline & \multicolumn{2}{|c|}{ Census Data 1999} & \multicolumn{5}{|c|}{ Freight-related activities, SIRENE 2004} \\
\hline & \multirow{2}{*}{$\begin{array}{c}\text { Population } \\
\text { millions }\end{array}$} & \multirow{2}{*}{\begin{tabular}{|l} 
Jobs \\
millions
\end{tabular}} & \multirow{2}{*}{$\begin{array}{c}\text { Plants } \\
\text { thousands }\end{array}$} & \multirow{2}{*}{$\begin{array}{l}\text { Jobs } \\
\text { millions }\end{array}$} & \multicolumn{3}{|c|}{$\%$ share of jobs } \\
\hline & & & & & Industry & Wholesale & Storage \\
\hline Paris Urban Area & 11,2 & 5,1 & 16 & 0,8 & $66 \%$ & $32 \%$ & $2 \%$ \\
\hline $\begin{array}{l}\text { Large Urban Areas } \\
+400000 \text { inhab. }\end{array}$ & 12,8 & 5,0 & 16 & 0,8 & $73 \%$ & $25 \%$ & $2 \%$ \\
\hline $\begin{array}{l}\text { Medium-sized Urban Areas } \\
100000 \text { - } 399999 \text { inhab. }\end{array}$ & 11,4 & 4,4 & 14 & 0,8 & $81 \%$ & $17 \%$ & $2 \%$ \\
\hline $\begin{array}{l}\text { Small Urban Areas } \\
40000 \text { - } 99999 \text { inha. }\end{array}$ & 5,4 & 2,2 & 8 & 0,4 & $85 \%$ & $14 \%$ & $2 \%$ \\
\hline $\begin{array}{l}\text { Very Small Urban Areas } \\
\text { Up to } 40000 \text { inhab. }\end{array}$ & 4,1 & 1,7 & 6 & 0,4 & $87 \%$ & $12 \%$ & $1 \%$ \\
\hline Rural Areas & 13,4 & 4,2 & 17 & 0,9 & $90 \%$ & $9 \%$ & $1 \%$ \\
\hline Total * & 58,3 & 22,7 & 78 & 4,1 & $81 \%$ & $18 \%$ & $1 \%$ \\
\hline
\end{tabular}

Source: INSEE, SIRENE (2004)

\section{Two units of measurement of flows}

Shipment and tonnage are the two units of measurement used in the present study. We chose shipment because it provides an enhanced level of observation for reconstituting traffic chains and is a logistical indicator of shipper practices. The tonnage was also considered because it is a classic value used in transportation research.

In our analysis, freight flows were restricted to the two ends of the shipping chain only. In other words, only the urban areas of origin, at the level of the shipping firm, and the urban areas of destination, at the level of the consignee firm, were only considered. Intermediate logistics platforms in urban areas through which these shipments may transit are not included, because we are only concerned with logistics rather than production or consumption. Our results do not take into account the internal flows within urban areas.

\section{Two sectors of activity}

To make our findings statistically representative by territory and economics and to overcome the deficiency in the shipper survey's source data, we aggregated the 36 sectors of activity covered in the survey into two sectors: wholesale trade and manufacturing.

The wholesale sector in our study includes wholesale trade in intermediate goods, production, and consumer goods. Warehousing and mail-order sales are also included in wholesale trade.

The manufacturing sector in our classification includes industries that deal with chemicals, specialty chemicals, metallurgy, waste processing, construction, object manufacturing, and the automotive, agri-food, pharmaceutical, etc.. 
The division of activities into two categories conceals heterogeneity within the categories themselves. In order to avoid misinterpretations caused by this lack of homogeneity, we geographically linked the main components of each of the two categories (manufacturing and wholesale trade). Where geographical linking is not possible, for example between the automotive industry and chemicals within the manufacturing sector, the different geographical distributions have been highlighted (appendix B).

\section{THE LOCATION OF MANUFACTURING AND WHOLESALE TRADE IN FRENCH URBAN AREAS}

The geographical location of manufacturing and wholesale trade in France is detailed in this section. It gives a brief overview of the current territorial distribution of the economic activities that generate freight flows in France.

At the national level, location issues are well documented in the literature through models and theories (Polèse, Shearmur, 2009). The location of economic activities is usually chosen depending upon on the location of natural resources, production factors (including labor), transport costs, and markets. In other words, firms make a trade-off between the proximity advantages and scale advantages when choosing the location of economic activity. However, the relative importance of these factors varies from one business sector to another. To illustrate this diversity, we look into where the main components of manufacturing and the wholesale trade at located at different levels of the urban hierarchy. The geographical distribution of the activities is deduced from the number of jobs.

\section{Wholesale trade activities are mainly located at the higher levels of urban hierarchy}

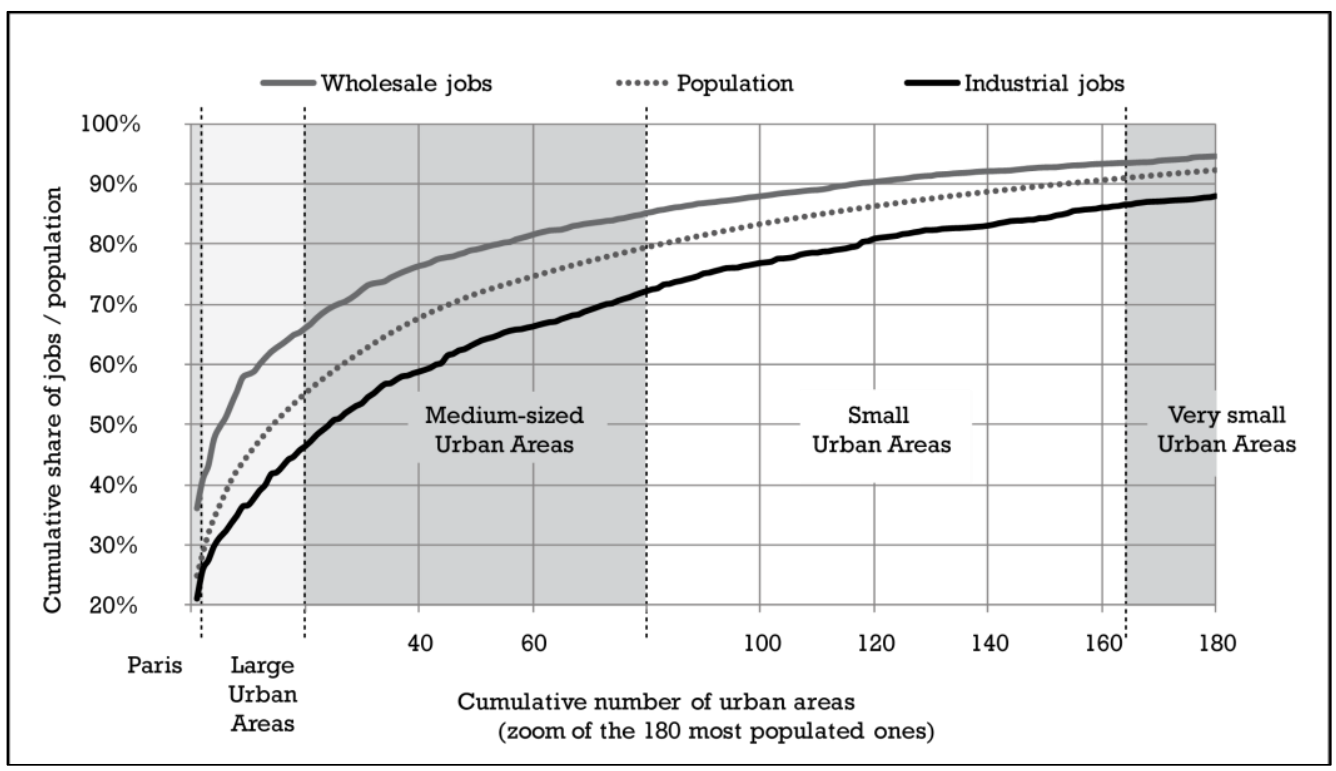

Source: INSEE, SIRENE (2004)

Figure 1 - Cumulative percentages of jobs in wholesale trade and in manufacturing within urban areas 
In our study, manufacturing activities constitute $81 \%$ of the jobs. These activities take place all locations represented by five levels of urban hierarchy described earlier, but are highly concentrated in smaller urban areas: urban areas with a population of less than 100,000 account for $25 \%$ of manufacturing jobs whereas they have only $20 \%$ of the total population (figure 1). There are a number of factors that can be used to explain the presence of manufacturing activities in urban areas of very different sizes. Sometimes, firms are prepared to pay the costs arising from locating their plants in urban areas so that they can be closer to their markets and suppliers. At times, firms opt for smaller towns to run their operations in view of lower real estate and labor costs (Polèse, Shearmur, 2009). These corporate choices therefore give rise to a wide variety in manufacturing location strategies. By contrast, wholesale trade activities are highly concentrated in locations higher in urban hierarchy, although their location varies from one specific subsector to another. If wholesale trade in non-food consumer products is considered, it is an essentially metropolitan activity (appendix B) and so the Paris urban area alone accounts for $51 \%$ of jobs in this sector. Wholesale trade in production goods is also concentrated in locations at higher level of urban hierarchy as evident by the fact that $60 \%$ of workers in this sector work in Paris and in urban areas having a population of more than 400,000 . Now it is obvious that the location of wholesale trade activity is very closely linked with population size unlike manufacturing.

The hierarchical approach developed here shows the location strategies of firms engaged in wholesale and manufacturing activities, but it is inadequate to explain the location choices adequately because it considers the different levels of hierarchy as homogeneous groups of urban areas. So the analysis should also include a regional analysis of business location.

\section{A typical North-East/South-West manufacturing split, but only affecting small and very small urban areas}

In Figure 2, the general profile of activity in urban areas is mapped by measuring the proportion of people working in wholesale trade using the national average as a reference. Simply put, the reverse of this map holds good for the other activity in our research, namely, manufacturing. Many large and medium-sized urban areas present an average profile, particularly the Paris region and eastern France. This makes it obvious that these urban areas, e.g. Lyon, retain a significant proportion of manufacturing jobs, unlike most other urban areas of comparable size. Conversely, other urban areas have a greater concentration of wholesale trade jobs than the national average. For example, Paris alone has $32 \%$ of jobs in the wholesale trade sector. Similarly, most of the large urban areas, such as Lille, Marseille, Strasbourg, Bordeaux, Nice and Toulouse, demonstrate a very high degree of specialization in this sector. Figure 2 also shows how medium-sized and small residential urban areas specialize in wholesale trade activities, particularly those on the Mediterranean coast. A majority of tourists, unemployed, and retired people in Languedoc-Roussillon and the French Riviera explains this feature.

Region-wise analysis reveals that wholesale trade is less concentrated in many urban areas in north-east France. This is a trend from French industrial history since the metallurgical, refining, automotive, and chemical industries mostly grew in the north-eastern regions of France in the 19th and 20th centuries. Even now, the trend continues keeping manufacturing 
activities in medium-sized and small urban areas in those regions. In contrast, manufacturing activities are sparser in the west and south of France, although certain smallurban areas may have local concentrations of manufacturing jobs (agri-food industry, home appliances, etc.).

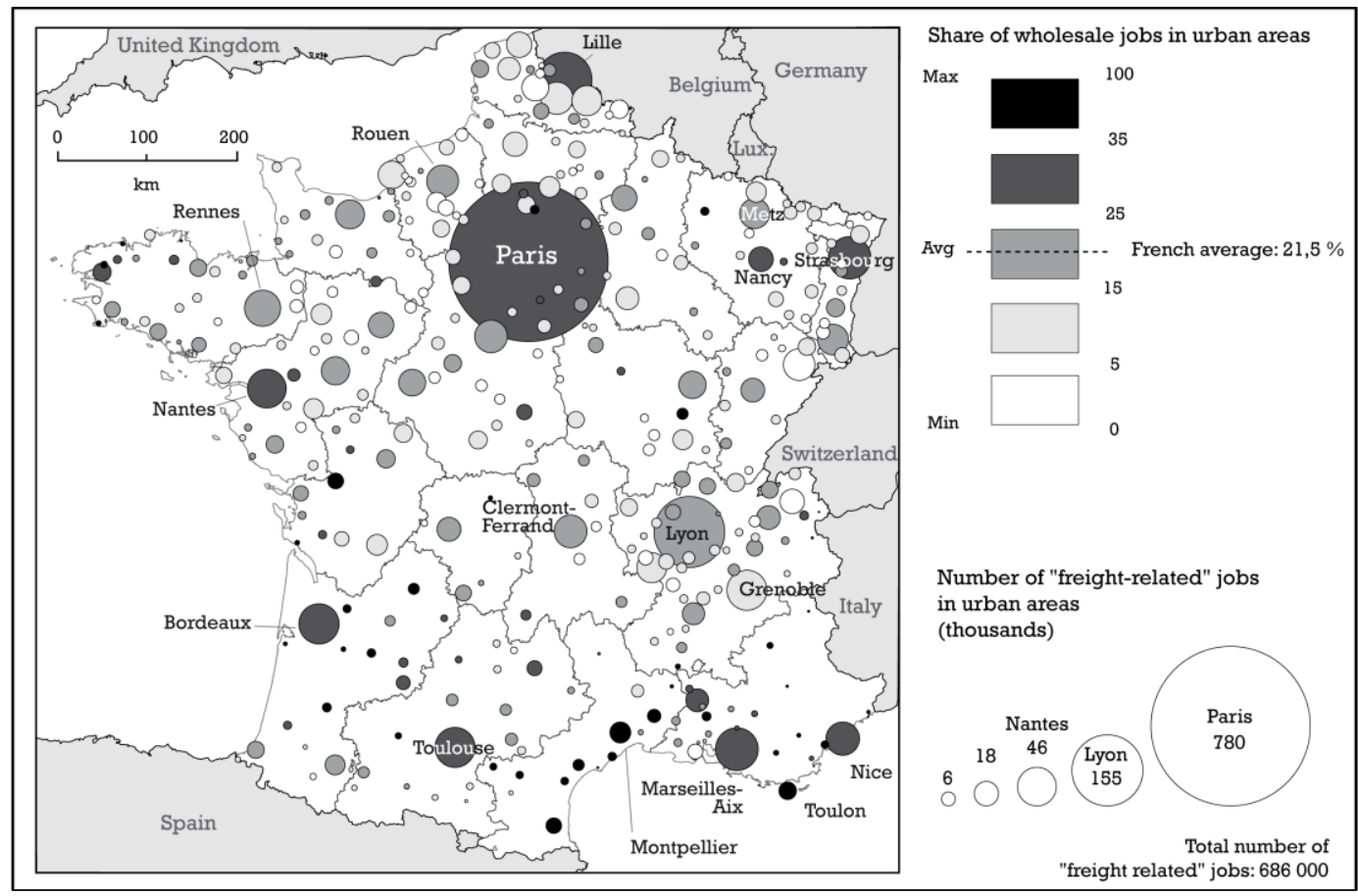

Figure 2 - Presence of wholesale trade activities in urban areas. Source INSEE, SIRENE (2004)

\section{THE ORGANISATION OF FREIGHT FLOWS BETWEEN THE LEVELS OF HIERARCHY}

The hierarchical and/or horizontal interrelations between urban areas according to their sizeclass are explored in this part. We analyze if the jobs and the flows exhibit similar location patterns. The location pattern of economic activities should theoretically be reproduced in the pattern of freight flows by urban areas forming networks of either a horizontal or hierarchical kind.

\section{Flows are globally correlated with jobs}

The volumes of goods exchanged between urban areas in France are rather correlated with the number of jobs in those urban areas, with some exceptions (figure 3a). Flows are slightly underrepresented in Paris and the urban areas having a population of more than 400,000 . They contribute less to shipments (33\%) and tons $(28 \%)$ and more to jobs (40\%). By way of a corollary, this first finding confirms the importance of urban areas at the bottom of the urban hierarchy and of rural areas in structuring the geography of freight flows. In particular, the findings emphasize the structural role of medium-sized urban areas, in terms of both shipments and tonnage, and the rural areas, in tonnage but not in shipments. It also should be added that in these two levels (medium-sized urban areas and rural areas) inbound and outbound shipments are extremely unbalanced (figure $3 b$ ). 


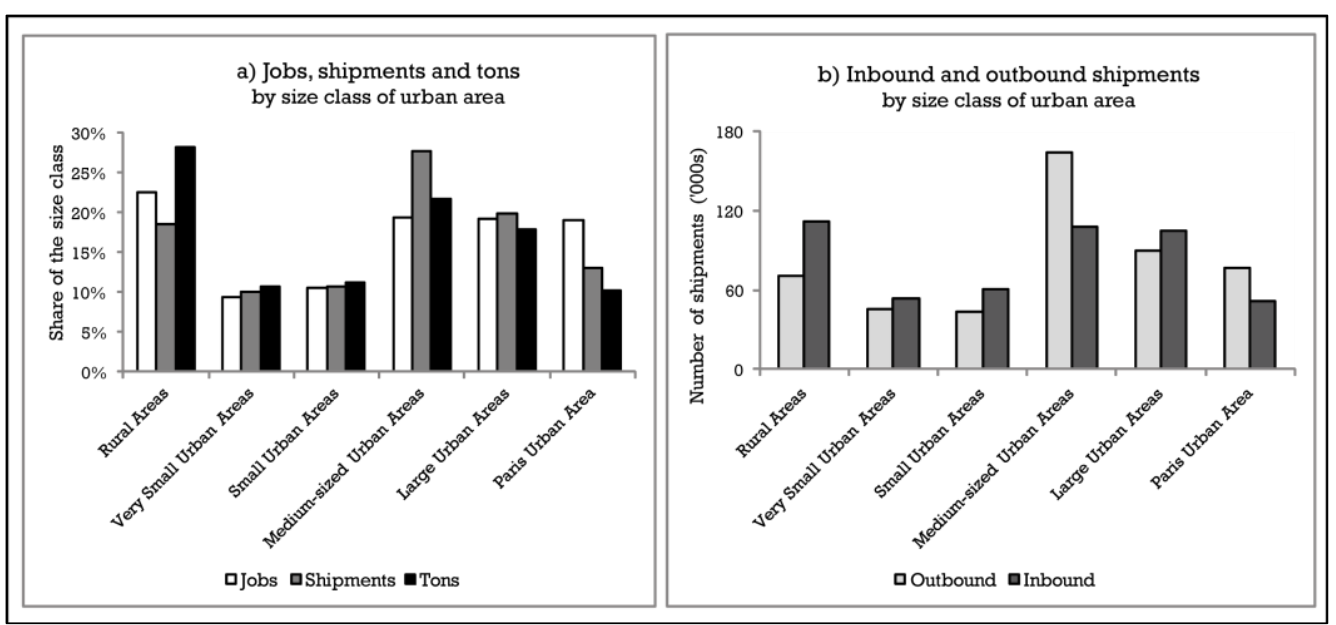

Figure 3 - (a) Share of each class size in jobs, shipments and tons. (b) Number of inbound and outbound shipments by size class. Source: ECHO, IFSTTAR (2004), SIRENE, INSEE (2004)

Table II - Outbound and inbound indices for shipments and tonnage by size of urban area

\begin{tabular}{|c|c|c|c|c|}
\hline & \multicolumn{2}{|c|}{\begin{tabular}{|l|} 
Emission index* \\
\end{tabular}} & \multicolumn{2}{|c|}{ Reception index* } \\
\hline & \begin{tabular}{|l|} 
Shipments \\
\end{tabular} & Tons & Shipments & Tons \\
\hline Paris Urban Area & 82 & 54 & 55 & 54 \\
\hline $\begin{array}{l}\text { Large Urban Areas } \\
+400000 \text { inhab. }\end{array}$ & 95 & 85 & 111 & 102 \\
\hline $\begin{array}{l}\text { Medium-sized Urban Areas } \\
100000-399999 \text { inhab. }\end{array}$ & 170 & 126 & 113 & 95 \\
\hline $\begin{array}{l}\text { Small Urban Areas } \\
40000 \text { - } 99999 \text { inha. }\end{array}$ & 86 & 71 & 119 & 145 \\
\hline $\begin{array}{l}\text { Very Small Urban Areas } \\
\text { Up to } 40000 \text { inhab. }\end{array}$ & 101 & 145 & 117 & 85 \\
\hline Rural Areas & 64 & 124 & 101 & 127 \\
\hline
\end{tabular}

\begin{tabular}{|l|l|l|l|l|}
\hline Total & 100 & 100 & 100 & 100 \\
\hline
\end{tabular}

* Ratio between the share of the size-class in flows and the share of the size-class in jobs. Inland France, excluding Corsica and Overseas Territories

Source: ECHO, IFSTTAR (2004), SIRENE, INSEE (2004)

The relationship between flows and jobs vary depending on the direction of flows: inbound and outbound (table II). Only urban areas with a population of 100,000 to 400,000 display a positive balance both on shipments and tonnage. The emission indices, defined as the ratio between the proportion of outbound flows observed and the proportion of jobs, show that small urban areas, Paris, and even more rural areas, generate few shipments (index below 100). Conversely, when weight of goods is used as a measure, rural areas and very small and medium-sized urban areas generate an enormous outbound tonnage (index above 100). An analysis based on the reception indices, defined as the ratio between the proportion of inbound flows and the proportion of jobs, shows that both inbound and outbound shipments and tonnage are massively underrepresented in Paris. And finally, the data show an overrepresentation of tonnage entering rural areas and small urban areas.

These initial findings confirm the importance of the small urban areas in the French productive system (appendix C). It becomes evident that freight flows are not exclusively polarized by the biggest urban areas. The system is not most dominated by Paris and the 
regional centres, but activities take place at all levels of urban hierarchy, with significant connections to secondary UAs and rural areas.

The hypothesis of the hierarchy now needs to be explored through the origindestination matrix.

\section{A system dominated by vertical flows}

Our analysis of the shipments reveals that one in two shipments originate from a higher ranked urban center to a lower ranked urban center and one in three from a lower to a higher ranked urban entity (table III). Given this background, the most intense flows in shipments and tonnage originate from medium-sized urban areas and reach rural areas (downward flows) (figures $4 a$ and $4 b$ ). Interurban exchanges between medium-sized urban areas (horizontal flows) and also from these toward large urban areas (upward flows) structure the formation of urban networks. By contrast, rural areas and small and very small urban areas feature only a few exchanges with same-ranked entities, but more with other levels in the hierarchy. The matrix also highlights the extent of the tonnage carried from rural areas to small, medium-sized, and large urban areas.

\begin{tabular}{|c|c|c|c|c|c|c|}
\hline & \multicolumn{2}{|c|}{ Manufacturing } & \multicolumn{2}{|c|}{ Wholesale trade } & \multicolumn{2}{|c|}{ Total } \\
\hline & Shipments & Tonnage & Shipments & Tonnage & Shipments & Tonnage \\
\hline Upward flows & $52.5 \%$ & $60.6 \%$ & $24.9 \%$ & $40.0 \%$ & $35.3 \%$ & $48.3 \%$ \\
\hline Downward flows & $36.1 \%$ & $30.9 \%$ & $61.1 \%$ & $53.3 \%$ & $52.0 \%$ & $43.7 \%$ \\
\hline Horizontal flows & $11.4 \%$ & $8.5 \%$ & $14.0 \%$ & $6.7 \%$ & $12.7 \%$ & $8.0 \%$ \\
\hline Total & $100.0 \%$ & $100.0 \%$ & $100.0 \%$ & $100.0 \%$ & $100.0 \%$ & $100.0 \%$ \\
\hline
\end{tabular}

Source: ECHO, IFSTTAR (2004)

The last finding relates to the relationship between the size of urban areas and flow distance, a hierarchical indicator of the range of interaction between urban areas. The results show that catchment areas of urban centers are proportional to their population size (figure 4c) and this applies only for inbound flows (both shipments and tons). The median distance of inbound shipments varies between $77 \mathrm{~km}$ (for rural areas) and $340 \mathrm{~km}$ (for large urban areas).

Outbound flows follow a different pattern: catchment areas correlate less with the size of the urban area. The median distance of outbound shipments varies between $130 \mathrm{~km}$ for medium-sized towns and $311 \mathrm{~km}$ for Paris.

This overall analysis provides empirical evidence of hierarchical organization of freight flows between urban areas. The hierarchical pattern of flows confirms our main hypothesis. The findings do not throw light on the causes, but only on the consequences in the spatial organization of freight flows. A more detailed approach to flows by type of activity can contribute to a better understanding of the causes of this configuration. 


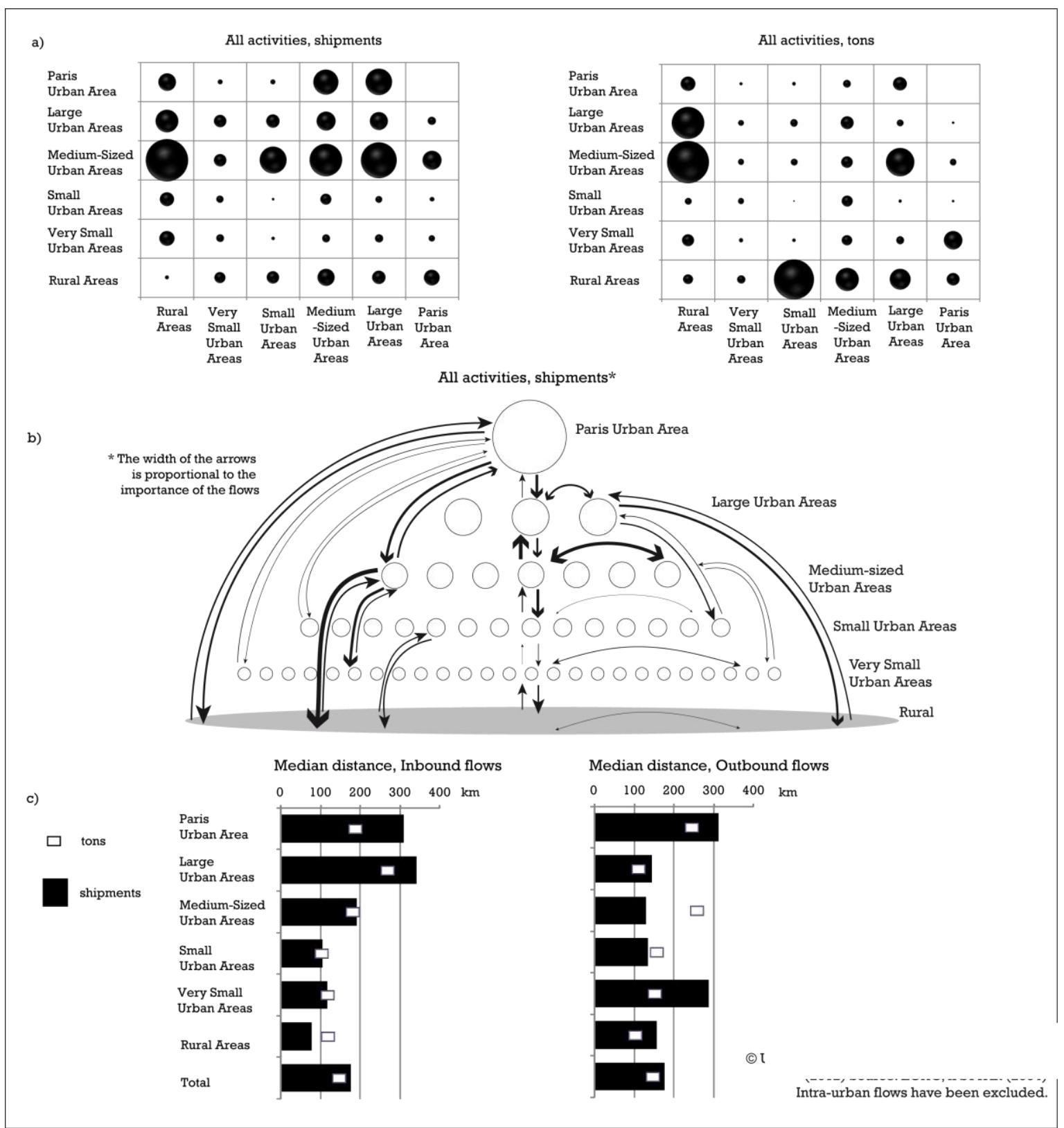

Figure 4. - Diagram of freight flows between urban areas, aggregated by size class. Source: ECHO, IFSTTAR (2004)

\section{Upward flows dominate in the manufacturing system}

Most manufacturing flows are upward in character (figure $5 \mathrm{~b}$ ). The vast majority of flows reach urban centers with a population of more than 100,000: $67 \%$ of shipments and $48 \%$ of tonnage. This finding leads to the observation that numerous manufacturing flows are from medium-sized to large urban areas and to Paris (figure 5a). Similarly, manufacturing flows originating from rural areas firstly bound to medium-sized towns and secondly to Paris demonstrate the importance of upward manufacturing flows. However, these observations do not discount the existence of horizontal flows between medium-sized towns, and a few downward flows, in particular from medium-sized towns toward rural areas.

The shipments generated by manufacturing activities are usually carried over long distances as evident by the fact that $50 \%$ of these shipments have their destination beyond $308 \mathrm{~km}$. 
Their scope varies proportionally with the size of the urban areas (figure $5 \mathrm{c}$ ) but only for inbound flows (both shipments and tons). This can be explained by the overall geographic organization of the manufacturing system. Manufacturing activities in small towns and rural areas are often tributary of local inputs of raw materials (i.e., agricultural products). The bulk of the raw materials are often carried over short distances. Conversely, intermediate goods and finished products, mainly meant for larger urban areas, are conveyed over longer distances.

Outbound distances are more or less the same for all levels of urban areas (between 265 and $340 \mathrm{~km})$, except Paris $(418 \mathrm{~km})$. This can be explained by the fact that manufacturing outputs are all carried over long distances, and the town size is not a factor. Globally, the national catchment areas observed above are the outcome of a strong regional specialization of manufacturing.

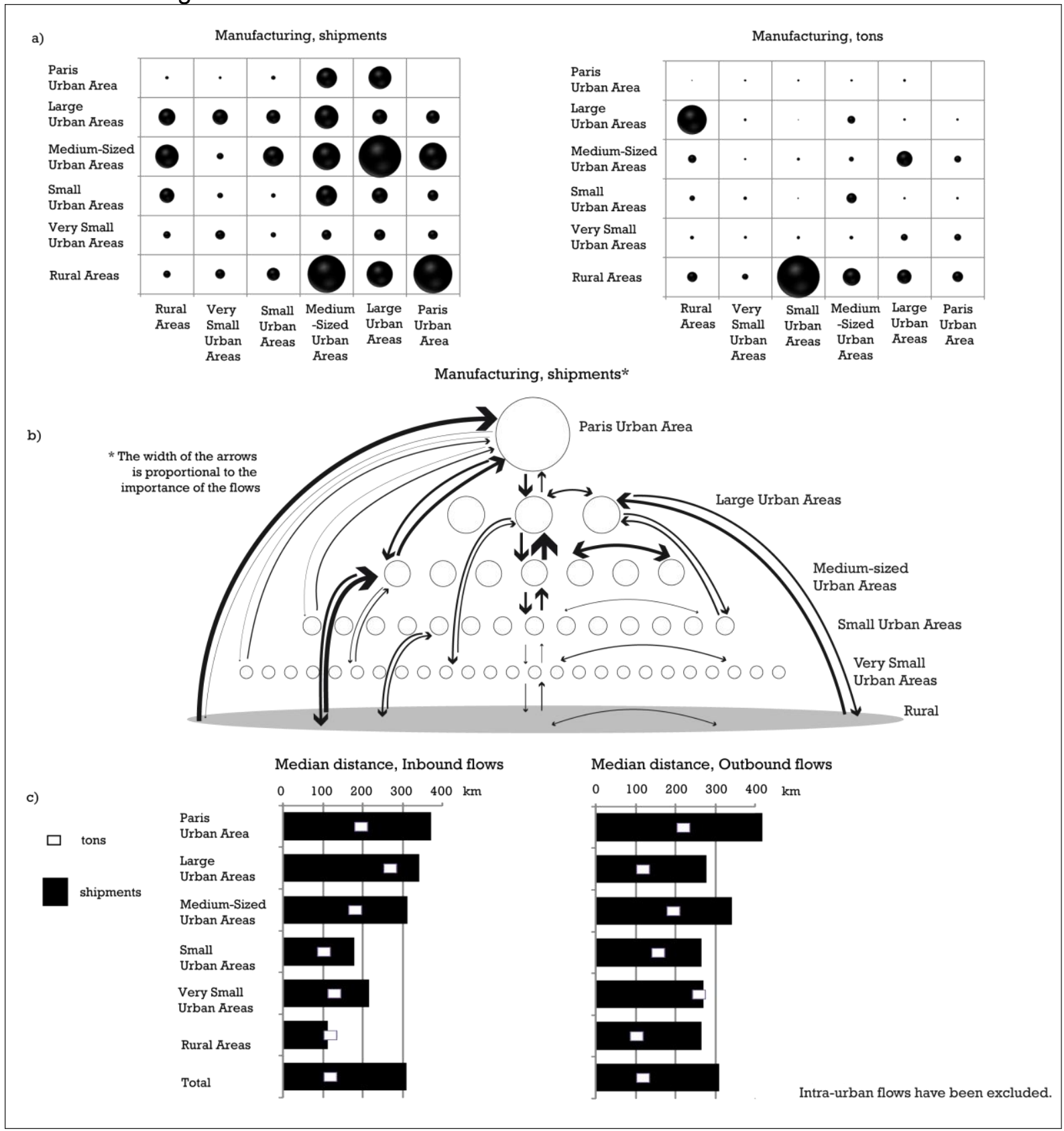

Figure 5 - Diagram of manufacturing flows between urban areas, aggregated by size class. Source: ECHO, IFSTTAR (2004) 


\section{Downward flows dominate in the wholesale trade sector}

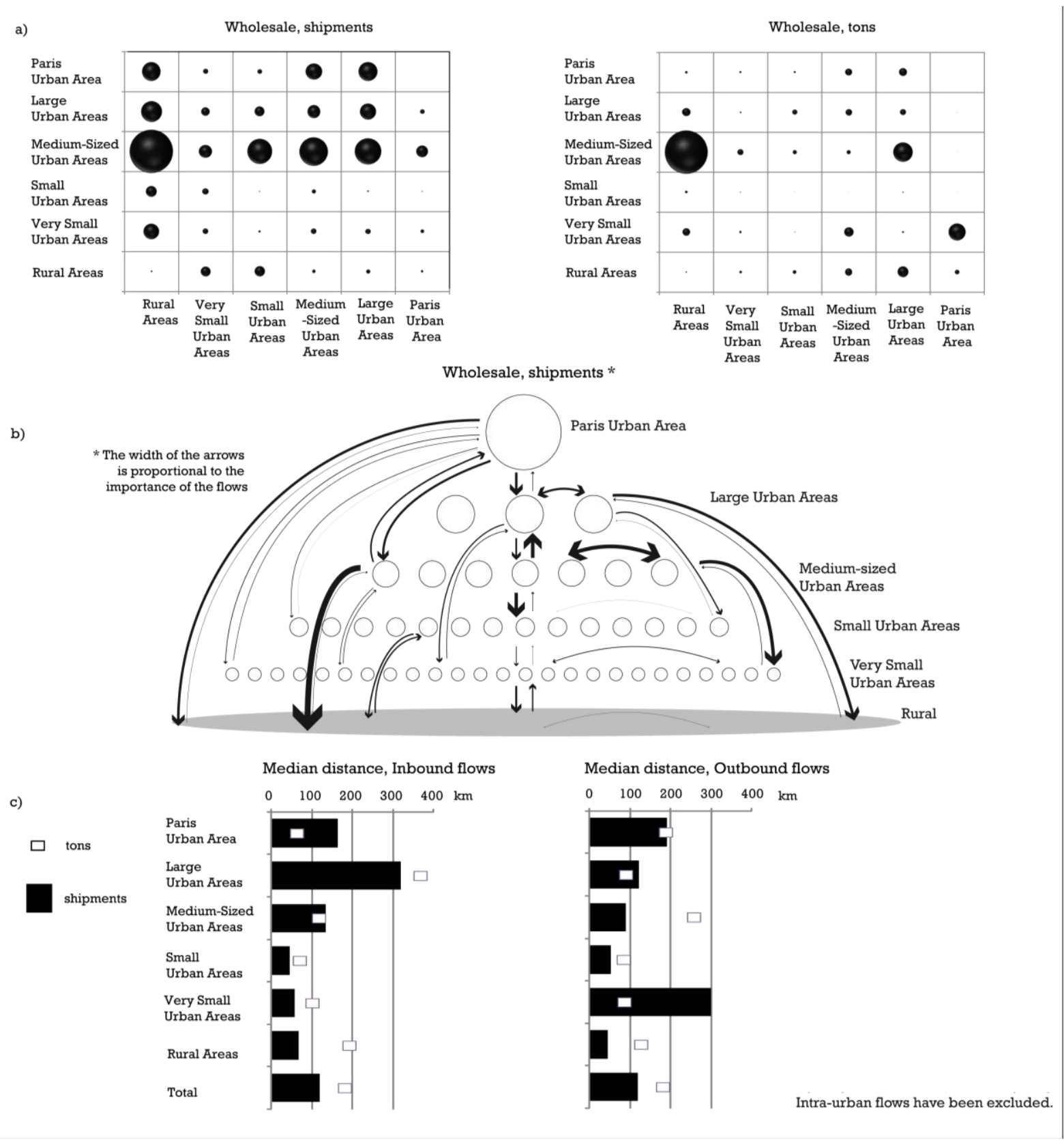

Figure 6 - Diagram of wholesale trade flows between urban areas, aggregated by size class. Source: ECHO, IFSTTAR (2004)

In contrast with manufacturing, wholesale trade shows a downward hierarchical pattern (figure 6b). More than six in ten shipments are dispatched to a destination town smaller than the originating urban area. Most shipments originate from towns with a population of more than 100,000 , in particular medium-sized towns. These send $12 \%$ of shipments and $22 \%$ of tonnage to rural areas (figure 6a). This means that wholesale trade flows are highly structured by large urban areas. The primary destination in wholesale trade is the rural area, which on its own attracts $30 \%$ of shipments and $33 \%$ of tonnage, but also, to a lesser degree, the large and medium-sized towns. 
In comparison with the national scope of manufacturing catchment areas, wholesale trade areas are rather local in nature (figure 6c). This type of trade activity is organized as most complex of services, mostly localized at the higher levels of urban hierarchy. Wholesale trade activities play an important role in redistributing freight flows, as they facilitate the link between buyers and sellers at the local level (Polèse, Shearmur, 2009). Therefore, wholesale trade flows tend to occur over relatively short distances: half of the shipments is conveyed over a distance of less than $119 \mathrm{~km}$. Catchment areas are particularly small at the lower levels of urban hierarchy: $50 \%$ of their shipments travel less than $70 \mathrm{~km}$. Outbound catchment areas of wholesale trade are proportional to the size of urban areas and reveal the central place structure: wholesale trade in large urban areas tends to be more scarce and complex than in small urban areas. The exceptionally long distances of outbound flows from very small urban areas $(299 \mathrm{~km})$ is partly explained by the specific concentration of niche products of wholesale trade at these places (i.e., drinks, forestry products) whose scope is rather national.

\section{CONCLUSION}

This paper has provided a novel analysis of the organization of freight flows between French urban areas using original survey as the basis. This research has provided empirical evidence to confirm theoretical assumptions on production systems. The conclusions of this study may be broadly be grouped into the three following topics: (1) the hierarchical nature of interurban freight flows; (2) the interlocking subsystems in wholesale trade; (3) the regional specialization in manufacturing production systems.

- Catchment areas of urban areas vary directly with their population size. This relationship has been verified both for shipments and tonnages. Vertical linkages are predominant: more than one in two shipments reach a lower ranked urban center and more than one in three is destined for a higher ranked urban center.

- Wholesale trade broadly reflects the traditional spatial organization of a market servicing activity, with interlocking areas of influence. Its flows are highly structured by the largest urban area, which redistributes goods to centers at other levels in the urban and rural hierarchy. Catchment areas of wholesale trade are proportional to the size of the urban areas and reveal the central place structure: wholesale trade in large urban areas tends to be more scarce and complex than in small towns. Obviously, not all the subsectors of wholesale trade are equally organized and niches exist (i.e. agricultural products, drinks, mail-order sales), but they are marginal compared to the main wholesale activities (i.e. consumer goods, capital goods, food).

- On the one hand, manufacturing is a supply chain servicing activity. In most of sectors, production units are concentrated in just a few local regions. Automotive or industrial equipment manufacturing, for example, is located in the northern part of the country. But fresh-food processing industry is mainly located in north-west France. On the other hand, manufacturing outputs are ubiquitously distributed. This regional specialization of manufacturing leads to a superposition and entanglement of catchment areas that are large overall: $50 \%$ of shipments are carried beyond $308 \mathrm{~km}$. Their size is almost the same on every level of urban hierarchy, except Paris. The manufacturing activities in the capital (i.e. pharmaceutical industry, printing) seem to 
be slightly more national-oriented than those in the rest of the territory. The sourcing distance (inbound flows) varies proportionally with the size of urban areas, both for shipments and tonnages. Manufacturing activities located in rural areas and little towns often act as a tributary of local inputs of raw materials (i.e., agricultural products), which are generally carried over short distances. Manufacturing activities located in medium and large urban areas do not feature local inputs of materials, and sourcing distances therefore tend to be longer.

- The downward-oriented flows of wholesale trade can be explained as a function of interface between global and regional sourcing entering a national economy through its gateways. This distribution hierarchy reflects the national urban system since the largest markets get priority in the distribution system.

- Moreover, it should be highlighted that many of the outputs of manufacturing are inputs for wholesale trade. The majority of manufacturing flows involve parts and semi-finished goods that are not distributed to the market but to other manufacturing units, or to large purchasers who then coordinate the distribution of these goods. The exception could be certain fresh food products (i.e. dairy), which, in their final form (ready for consumption), have a market-based distribution structure, similar to wholesale trade.

The year of observation considered for our analysis is 2004. Since then, the relocation of European manufacturing to developing countries has probably contributed to a shift in freight flows from manufacturing to wholesale trade and longer distances. The reorganization of French and European distribution centres (Hesse, 2006, Raimbault and Bahoken, 2013) and the development of e-commerce (Weltevreden and Boschma, 2008) could have modified the pattern of wholesale trade flows. At the time of writing this paper, it was still too early to fully assess the consequences of the financial crisis of 2008 on the hierarchy of freight flows. Reconfigurations in road transport market already have led to a decrease of freight volumes and a transformation of distribution networks. The resulting cargo consolidation could mean that larger urban areas and their evolved transport systems are placed in a better position than small and medium-sized urban centers. It is however not entirely clear at this point to what extent these changes will affect the hierarchy of freight flows and might lead to a paradigm shift.

\section{ACKNOWLEDGEMENTS}

This research has benefitted from financial support of the French Ministry of Transport in the framework of the research project ECHO TMV: "Contribution of the 2004 shipper survey to city freight issues", coordinated by Michèle Guilbault (University Paris Est, IFSTTAR, SPLOTT). The authors would like to thank the reviewers for their comments that helped in the improvement of the manuscript. 


\section{BIBLIOGRAPHY}

Beaverstock, J. V., Smith, R. G., and Taylor, P. J. 1999. A roster of world cities. cities, 16(6), 445-458.

Dablanc, L.., Ross, C. 2012. Atlanta: a mega logistics center in the Piedmont Atlantic Megaregion PAM. In: Journal of transport geography 24, 432-442.

Dobruszkes, F. 2006. An analysis of European low-cost airlines and their networks. Journal of Transport Geography, 14(4), 249-264.

Friedmann, J. 1986. The world city hypothesis. Development and change, 17, pp 69-83.

Godlund, S. 1956. The Function and Growth of Bus Traffic within the sphere of Urban Influence, Lund, Series in Human Geography, No. 18, 80 p.

Goetz, A. R. 1992. Air passenger transportation and growth in the US urban system, 19501987. Growth and Change, 23(2), 217-238.

Goetz, A. R., and Graham, B. 2004. Air transport globalization, liberalization and sustainability: post-2001 policy dynamics in the United States and Europe.Journal of Transport Geography, 12(4), 265-276.

Goetz, A. R., and Vowles, T. M. 2009. The good, the bad, and the ugly: 30 years of US airline deregulation. Journal of Transport Geography, 17(4), 251-263.

Green, H.W. 1958. Community of Interest Areas: Notes on the Hierarchy of Central Places and their Hinterlands, Economic Geography, Vol. 34, 210-226

Guilbault, M., Soppé, M. 2009. Apports des enquêtes chargeurs. Connaissance des chaînes de transport de marchandises et de leurs déterminants logistiques. Lavoisier, Paris.

Guilbault, M., Gouvernal, E. 2010 Transport and logistics demand: New inputs from large shipper's surveys in France, Transport Research Record, Volume 2168 / 2010, 71-77.

Hall, P. 1993 Forces shaping urban Europe. Urban studies, 30(6), 883-898.

Hesse, M. 2006 Global chain, local pain: Regional implications of global distribution networks in the German north range. Growth and change, 37(4), 570-596.

Ivy, R. L. 1993 Assessing changes in air service connectivity in the US Southeast, 19781992. Southeastern Geographer, 33(2), 148-158.

Lee, J., Chen, L., and Shaw, S. L. 1994. A method for the exploratory analysis of airline networks. The Professional Geographer, 46(4), 468-477.

Lyons, D., and Salmon, S. 1995. World cities, multinational corporations, and urban hierarchy: the case of the United States. World Cities in a World-system, 98-114.

Neal, Z. P. 2011. From central places to network bases: A transition in the US urban hierarchy, 1900-2000. City and Community, 10(1), 49-75.

Polèse, M., Shearmur, R. 2009. Economie urbaine et régionale. Introduction à la géographie économique. Economica, $438 \mathrm{p}$.

Pumain, D. 1992. Urban networks versus urban hierarchies-comment. Environment and Planning A, 24(10), 1377-1380.

Raimbault, N., and Bahoken, F. (2013). Quelles places pour l'économie des biens matériels dans les espaces métropolitains? L'exemple des territoires logistiques du Bassin parisien. Territoire en Mouvement, (22).

Rozenblat, C., and Pumain, D. 1993. The location of multinational firms in the European urban system. Urban Studies, 30(10), 1691-1709.

Sassen, S. 1994. Cities in a world economy (Vol. 3). Thousand Oaks, CA: Pine Forge Press. 
Shaw, S. L. 1993. Hub structures of major US passenger airlines. Journal of Transport Geography, 1(1), 47-58.

Smith, D. A., and Timberlake, M. F. 2001. World City Networks and Hierarchies, 1977-1997 An Empirical Analysis of Global Air Travel Links. American Behavioral Scientist, 44(10), 1656-1678.

Taaffe, E.J. 1962. The Urban Hierarchy: An Air Passenger Definition, Economic Geography, Vol. 38, 1-14.

Zipf, G. K. 1941. National unity and disunity: the nation as a bio-social organism. The Principia Press

Weltevreden, J. W., and Boschma, R. A. 2008. Internet strategies and performance of Dutch retailers. Journal of Retailing and Consumer Services, 15(3), 163-178.

\section{APPENDICES}

Appendix A - Location of French Urban Areas, by size class

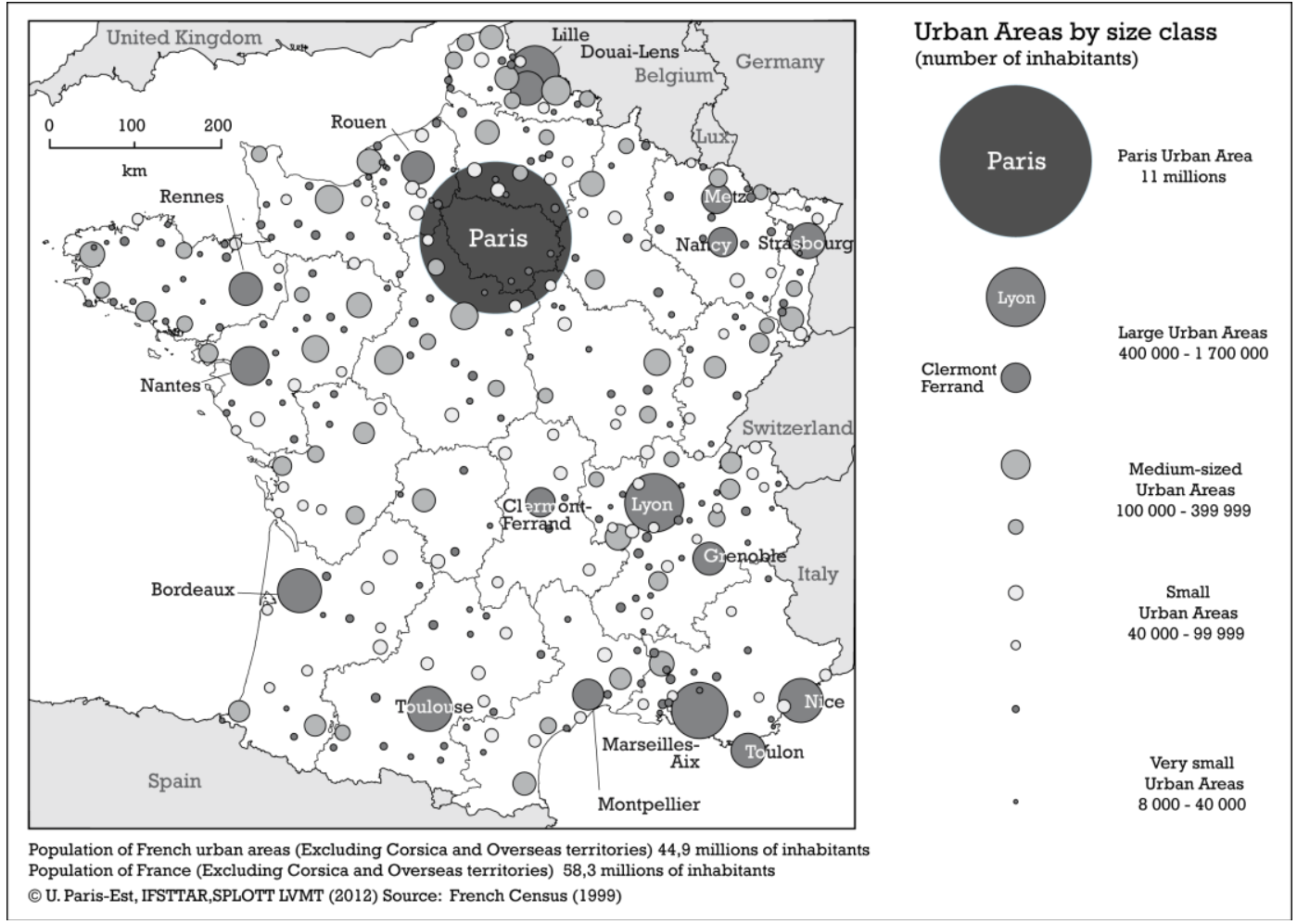

Source: French Census (1999). 
Appendix B - Location profiles of activities

\section{"Freight-related" Activities}

Al. Automotive Industry

A2. Industrial Equipment Manufacturing

A3. Electrical Machine Manufacturing

A4. Fresh Food Processing Industry

A6. Parachemistry

A7. Metalworking

A5. Dry Food Processing Industry

A. Total Manufacturing

Bl. Wholesale of consumer goods (non-food)

B2. Wholesale of capital goods

B. Total Wholesale

C. Total Storage

$\mathrm{A}+\mathrm{B}+\mathrm{C}$ "Freight-related" activities

Census Data (1999)

Jobs

Population
Location Profile of Jobs. Share of each size class of Urban Area

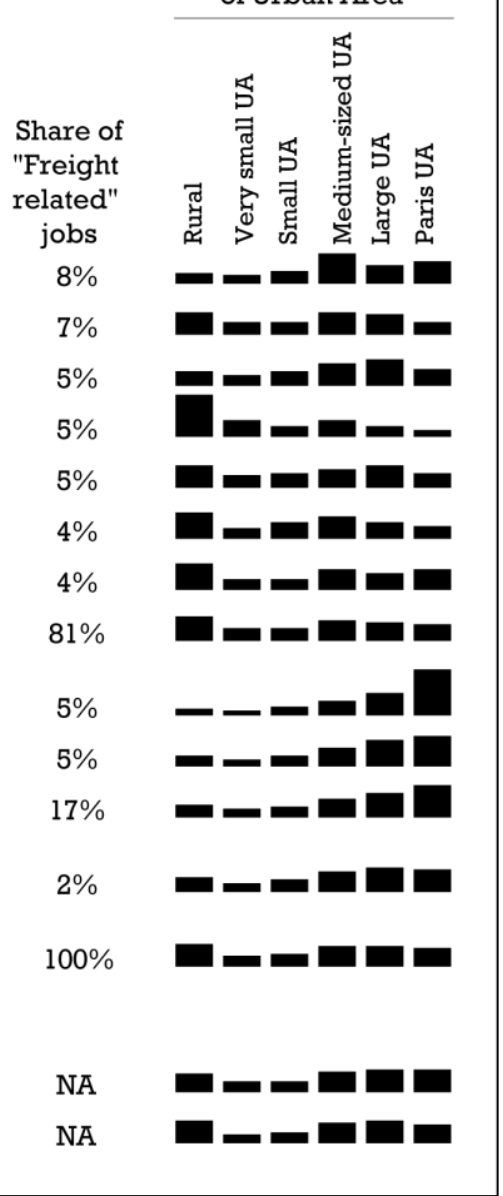

Source: INSEE, SIRENE (2004)

Appendix C - Outbound and inbound flows in millions) by size of urban area

\begin{tabular}{|c|c|c|c|c|c|c|}
\hline \multirow[b]{2}{*}{ In millions } & \multicolumn{2}{|c|}{ Outbound } & \multicolumn{2}{|c|}{ Inbound } & \multicolumn{2}{|c|}{ Outbound + Outbound } \\
\hline & Shipments & Tons & Shipments & Tons & Shipments & Tons \\
\hline Paris Urban Area & 76 & 65 & 51 & 66 & 127 & 131 \\
\hline $\begin{array}{l}\text { Large Urban Areas } \\
+400000 \text { inhab. }\end{array}$ & 90 & 105 & 105 & 125 & 195 & 230 \\
\hline $\begin{array}{l}\text { Medium-sized Urban Areas } \\
100000 \text { - } 399999 \text { inhab. }\end{array}$ & 164 & 159 & 108 & 119 & 272 & 278 \\
\hline $\begin{array}{l}\text { Small Urban Areas } \\
40000 \text { - } 99999 \text { inha. }\end{array}$ & 44 & 48 & 61 & 97 & 105 & 145 \\
\hline $\begin{array}{l}\text { Very Small Urban Areas } \\
\text { Up to } 40000 \text { inhab. }\end{array}$ & 46 & 87 & 53 & 51 & 99 & 138 \\
\hline Rural Areas & 71 & 179 & 111 & 183 & 182 & 363 \\
\hline Total* & 490 & 643 & 490 & 641 & 980 & 1284 \\
\hline
\end{tabular}

